\title{
$O$ corpo, a semente e o fruto: a antropologia paulina entre o simbólico e o conceitual em seu discurso sobre o ser humano e sua ressurreição The body, the seed and the fruit: The Pauline anthropology between the symbolic and the conceptual in his discourse on the human being and his resurrection
}

Carlos Queiroz ${ }^{1}$

Rodrigo Portella ${ }^{2}$

\section{RESUMO}

A modernidade, e particularmente a pós-modernidade, tem colocado em crise a identidade humana, seu "porquê" e "para quê". Diante de sociedades ocidentais cada vez mais descritianizadas e secularizadas, se faz necessário ao teólogo e ao cientista da religião o debruçar-se sobre as tradições religiosas para verificar o que veiculam em sua antropologia. No caso específico do presente artigo, a intenção é esclarecer como o cristianismo, particularmente o apóstolo Paulo, compreende o ser humano. Contudo, sendo esta tarefa que se encontra para além de um artigo, resta-nos esclarecer a visão de Paulo a respeito do ser humano a partir de um ponto que consideramos chave para sua antropologia: a ressurreição, o ser humano novo, particularmente descrito em 1Co 15. Entendemos que Paulo constrói muito de sua antropologia a partir da visão que tem sobre o futuro escatológico do ser humano, pois nele estaria a verdadeira medida do ser humano unido a Deus, isto é, sua realização plena. Contudo, para se chegar a esta visão prenunciada por Paulo, será preciso

${ }^{1}$ Mestre em Ciência da Religião pela UFJF.

${ }^{2}$ Doutor em Ciência da Religião (UFJF) com estágios de pós-doutoramento na PUC-Rio e Universidade do Minho, Portugal. Professor de Ciência da Religião na UFJF. E-Mail: rodrigo@portella.com.br. 
antes, ainda que de forma célere, percorrer alguns de seus conceitos ao referir-se ao ser humano, em várias situações, e compreender como tais conceitos constroem a antropologia paulina e apontam para sua concepção de ressurreição / novo ser humano.

\title{
PALAVRAS-CHAVE
}

Paulo de Tarso. Ressurreição. Antropologia paulina. Escatologia.

\begin{abstract}
Modernity, and particularly postmodernity, has put human identity in crisis, its why and for what. In the face of ever more decritianized and secularized Western societies, it is necessary for the theologian and scientist of religion to dwell on religious traditions to verify what they convey in their anthropology. In the specific case of the present article, the intention is to clarify how Christianity, particularly the apostle Paul, understands the human being. However, since this task is beyond an article, we can clarify Paul's view of the human being from a point that we consider to be key to his anthropology: the resurrection, the new human being, particularly described in 1Co 15. We understand that Paul builds much of his anthropology from the view he has on the eschatological future of man, for in him would be the true measure of the human being united to God, that is, his full realization. However, in order to arrive at this vision foretold by Paul, it will be necessary, even if quickly, to go through some of his concepts when referring to the human being in various situations, and to understand how such concepts construct Pauline anthropology and point out for his conception of resurrection / new human being.
\end{abstract}

\section{KEYWORDS}

Paul of Tarsus. Resurrection. Anthropology of Paul. Eschatology.

\section{Introdução}

O pensamento teológico do apóstolo Paulo tem suas raízes no judaísmo helenista de seu tempo. Isso, todavia, não permite supor que houvesse por parte do apóstolo adesão ao pensamento platônico. A abordagem 
antropológica paulina é o que se depreende de suas cartas e é nelas que estão centrados a sua teologia e o impacto, conforme sua interpretação, da revelação e da graça divinas sobre o ser humano. Em suas cartas é possível identificar afirmações teológicas e testemunhar o desenvolvimento progressivo do pensamento do apóstolo.

Udo Schnelle ${ }^{3}$ admite que a questão onipresente nas formações de sentido filosóficas e religiosas da Antiguidade em torno do que vem a ser o "ser humano" encontra em Paulo uma perspectiva que permite captar o ser humano e construir novas intelecções e soluções para a questão. No entanto, Dunn ${ }^{4}$ adverte que ler a antropologia paulina à luz do uso moderno ou do uso grego antigo provavelmente distorceria já desde o ponto de partida a apreciação do pensamento do apóstolo.

Considerando-se a influência do pensamento estóico na tradição sapiencial judaica, as visões grega e judaica do mundo, a influência platônica e o contraste entre os dois mundos em que transitava o apóstolo, a ideia predominante ao longo dos últimos cem anos foi a de que a dispersão do uso paulino reflete uma combinação de influências judaicas e helenísticas, numa e noutra medida. Isto é, que a ideia de carne como corpo material reflete o típico sentido hebraico de basar, enquanto a ideia de carne como antagonista a Deus é de natureza mais helenística. Essa questão em torno da antropologia paulina provocou e ainda traz à tona acalorados e prolongados debates sobre se o apóstolo teria recebido a influência de categorias helenísticas ou judaicas. É um pouco do que veremos adiante, desdobrando-se, ao final, com sua interpretação sobre a ressurreição enquanto ápice do ser humano a Jesus unido.

\section{A estrutura teológica e antropológica da escatologia paulina a partir do diálogo entre judaísmo e helenismo}

Dentre os termos antropológicos notáveis em Paulo podemos notar: soma / corpo, sarx / carne, psychê / alma, pneuma / espírito, nous / mente,

${ }^{3}$ SCHNELLE, Udo. Paulo: vida e pensamento. Santo André/São Paulo: Academia Cristã/Paulus, 2010.

${ }^{4}$ DUNN, James D. G. A teologia do apóstolo Paulo. São Paulo: Paulus, 2003. 
kardia/ coração e suneidesis / consciência. A partir do uso que Paulo faz de tais termos ao referir-se, em vários momentos e distintas situações, ao ser humano, pode-se considerar que a amplitude do termo "corpo" perpassa toda a teologia de Paulo.

Soma para Paulo expressa o caráter de "humanidade criada" - isto é, como "existência corporificada". É precisamente como corporificada, e por meio dessa corporificação, que a pessoa participa da criação e funciona como parte da criação. A corporeidade constitui a existência humana em sua qualidade de criatura. Contudo, devido à realidade do pecado, a corporeidade é para Paulo sempre também corporeidade ameaçada, de modo que ele distingue entre soma e sarx.

Dessa forma, a questão da corporeidade torna-se central na escatologia paulina e é plausível perceber o termo chave soma em três contextos temáticos: 1) como designação neutra da constituição corpórea do ser humano; 2) em um sentido qualificador negativo; 3) o uso positivo como uma expressão abrangente do self humano.

O soma é para Paulo a interseção entre a situação condicionada do ser humano no mundo e a atuação de Deus no ser humano. Presume-se, então, que para Paulo, não pode haver identidade humana sem corporeidade, de modo que ele pensa também a realidade da ressurreição de modo corpóreo e corporal. A relação com o mundo e a relação consigo mesmo estão intimamente relacionadas, a escatologia e a antropologia condicionam-se e complementam-se mutuamente. Assim, o conceito de corpo constitui a pedra fundamental da teologia de Paulo. Nos seus sentidos intimamente interligados, a palavra soma une todos os seus grandes temas.

Mas pensar o soma, de acordo com Schnelle ${ }^{5}$, é pensar também o seu par antropológico sarx, que é o outro termo antropológico paulino, depois de soma, mais importante. Sarx também pode ser identificado com um sentido neutro, designando a condição exterior do ser humano e dos demais animais, apontando para a matéria do corpo ou para o gênero humano na totalidade de tudo que é essencial à humanidade. E pode conotar também um sentido negativo, apontando para o ser humano que vive de si mesmo e confia em si mesmo ao âmbito da carne, caracterizando-se

5 SCHNELLE, 2010. 
como carnal em oposição ao espiritual. No entanto, Dunn ${ }^{6}$ e Fabris ${ }^{7}$ advertem que "carne" para Paulo não era nem não-espiritual e nem pecaminosa. O termo simplesmente indicava e caracterizava a fraqueza de uma humanidade constituída como carne e sempre vulnerável à manipulação dos seus desejos e necessidades como carne.

A tentativa de combinar elementos da antropologia hebraica e da antropologia grega numa nova síntese é admitida como resposta à significação teológica da distinção entre soma e sarx. Presume-se que Paulo afirmou a concepção hebraica mais holística da corporificação humana, com o que isso significava para a corporeidade e a socialidade da existência humana como parte integrante do fato de ser humano. Ao mesmo tempo reconheceu algo de importante na atitude grega mais negativa em relação à existência "na carne", que também queria afirmar. Nesse sentido, pode-se presumir que Paulo habilmente aproveita o sistema de convicções judaico e helenístico para inculturar o evangelho aos gentios.

A despeito da discussão da antropologia paulina concentrar-se em torno das duas palavras-chave: soma e sarx, no desenvolvimento paulino das reflexões antropológicas, psychêlalma e pneuma/espírito humano, adquirem significados relevantes, pois apesar de Paulo usar pouco os dois termos, o seu emprego tem certa importância para a avaliação da sua antropologia e a maneira como concebia a interface entre o divino e o humano. Como síntese, a compreensão geral é de que alma serve para designar a pessoa - sujeito de toda a ação do homem. Perder a alma é perder o todo. E espírito, por conseguinte, denota a vida procedente de Deus - princípio de vida e ação que dirige e controla o indivíduo humano.

Assim como os pares antropológicos soma e sarx, psychê e penu$m a$, outros termos mais destacados se apresentam em par natural como nous e kardia, "mente" e "coração", e apontam para aspectos distintos do self humano. Nous reflete a valorização tipicamente grega da razão ou racionalidade como aquilo que se relaciona com o divino, como participante do divino, como o divino na humanidade. Dessa maneira, Paulo aproveita claramente um lugar comum da filosofia grega: que a razão humana percebe a existência e a natureza de Deus racionalmente, sendo

6 DUNN, 2003.

7 FABRIS, Rinaldo. Paulo: Apóstolo dos gentios. São Paulo: Paulinas, 2001. 
mais ou menos um axioma da razão humana e na verdade um corolário inevitável do fato da própria racionalidade humana e kardia, por sua vez, é um termo mais caracteristicamente hebraico, mas igualmente grego, e em ambos os casos denota a parte mais íntima da pessoa, a sede das emoções, mas também do pensamento e da vontade.

A partir desses pressupostos antropológicos, a reflexão prossegue em torno da articulação entre as figuras de Adão e Cristo e da tensão antropológica e escatológica presumivelmente existente neles. O apóstolo dos gentios encerra toda a história humana nessas duas figuras arquetípicas, incorporando as duas únicas alternativas que o evangelho apresenta à humanidade.

A tropologia de Adão é definida por Schnelle ${ }^{8}$ como um claro paralelo entre Paulo e o judaísmo de seu tempo com o fim de mostrar sua compreensão do pecado. Desde o pecado de Adão, o mundo está marcado pela relação pré-estabelecida e todo-dominante entre pecado e morte, o que Dunn ${ }^{9}$ denominou "dolorosa condição humana" e o que todas as filosofias religiosas consideram como "um lado obscuro do caráter humano".

A avaliação paulina da condição humana em termos do poder do "pecado", do que esse poder produz no indivíduo e na sociedade, e como se entrosa com a realidade da morte e dá à morte o seu caráter apavorante e negativo tem relevância não só para a espiritualidade pessoal, mas também para outras análises da sociedade e todas as estratégias para construção da comunidade.

A análise pode facilmente ser descartada como demasiadamente dependente de um mito e cosmologia primitiva. Mas isso seria equivalente a confessar a pobreza de uma cultura incapaz de reconhecer o poder de tal mito e metáfora para moldar instintos e percepções humanas profundamente sentidas ${ }^{10}$.

A figura de Adão tem sido objeto de pensamentos especulativos tanto no judaísmo quanto no gnosticismo, na compreensão de

\footnotetext{
${ }^{8}$ SCHNELLE, 2010.

9 DUNN, 2003.

${ }^{10}$ DUNN, 2003, p. 826.
} 
Brakemeier ${ }^{11}$, a queda do primeiro ser humano e, por conseguinte, a origem de pecado e morte representavam um mistério em busca de respostas. É bem provável que tais paralelos histórico-religiosos tenham exercido influxo sobre a teologia cristã, seja na forma da ideia do patriarca que determina a sorte de seus descendentes, seja na do mito do proto-homem que prefigura o segredo da existência humana. A reflexão teológica cristã tinha que descobrir em Cristo o antítipo de Adão, em tudo contrário ao ancestral responsável pela desgraça da humanidade. Enquanto Adão afundou o ser humano em pecado e morte, Cristo o salvou. "Cristo como último Adão funciona na teologia de Paulo como a realização arquetípica e a medida do desígnio de Deus ao criar a humanidade"12.

Assim tem-se como corolário paulino que o pecado e a morte redundam da transgressão de Adão e definem a situação desesperadora na qual a humanidade se encontra e que precisa da intervenção radical de Deus, que ocorre por intermédio de Cristo, o "último Adão". Paulo indica que o pecado e a morte encontram parceiro na lei, parecendo a lei ser um poder que forma terrível triunvirato com os outros dois; Dunn admite que a função mais controversa da lei na teologia de Paulo é o seu papel de instrumento do pecado, isto é, a lei que, pela força do pecado, ultrapassando o seu papel de conscientizar do pecado, na realidade provoca a transgressão. Paulo sabia perfeitamente que atribuir tal papel à lei podia parecer identificar a lei com o pecado em si e assim condenar completamente a lei, por isso esforçou-se para defender a lei precisamente contra essa acusação. Dessa forma, no desenvolvimento do argumento traz a lume que a lei é apresentada com o papel de definir o pecado, mostrá-lo à consciência como transgressão e condenar esta transgressão.

Contudo a morte é tida como corolário natural do pecado. O fato é que a vida neste mundo não pode escapar da morte do mesmo modo como não pode escapar da carne, não pode escapar da morte do mesmo modo como não pode escapar do pecado. Não há saída senão através da morte, a morte do outro "um homem", que "os muitos" podem compartilhar,

${ }^{11}$ BRAKEMEIER, Gottfried. A Primeira Carta do Apóstolo Paulo à comunidade de Corinto: um comentário exegético-teológico. São Leopoldo: Sinodal/EST, 2008, p. 202-203.

12 DUNN, 2003, p. 814. 
do mesmo modo como participam da suscetibilidade de Adão ao pecado e à morte. Contudo,

a morte não é todo-poderosa. Foi despojada. Com isso perdeu o ferrão, o aguilhão (kentron). Não mais consegue de fato ferir. Tornouse incapaz de realmente aniquilar. A certeza da ressurreição degrada a morte à realidade penúltima. Ela tira a vida, sim, mas não mais mata. Tornou-se possível morrer em paz, com esperança de nova vida. Deus vai comutar o corpo mortal e revesti-lo de imortalidade ${ }^{13}$.

De importância não menor para a teologia de Paulo é a afirmação do seu evangelho de que em Cristo o poder das forças de dominação dos indivíduos e da comunidade foi decisivamente destruído e assim presume-se que Paulo tenha alcançado a superação das fronteiras de culturas e de pensamento, ao combinar o conceito judaico da ressurreição com a noção grega do espírito enquanto poder divino de vida aceitável no âmbito helenístico.

No tempo escatológico, Jesus Cristo exerce seu domínio universal em sua função como salvador e libertador. Sua alteza / soberania relativiza todas as outras pretensões, pois não é o imperador ou uma divindade cúltica que salvam. Paulo vive na certeza de que Deus agiu em Cristo para salvar a humanidade. Pela libertação do poder do pecado, da carne e da morte, os crentes participam da virada dos tempos inaugurada por Deus na morte e ressurreição de Jesus Cristo ${ }^{14}$.

\section{Ressurreição e imortalidade: a pregação pedagógica de Paulo}

Mazzarolo ${ }^{15}$ admite que a ressurreição é o "carro-chefe" de toda a teologia paulina, pois se não fosse a ressurreição, a missão não encontraria sentido. "Que a ressurreição era elemento fundamental na mensagem

${ }^{13}$ BRAKEMEIER, 2008, p. 217.

${ }^{14}$ SCHNELLE, 2010, p. 560-561,

${ }^{15}$ MAZZAROLO, Isidoro. Primeira Carta aos Coríntios, exegese e comentário. Rio de Janeiro: Mazzarolo Editor, 2008b, p. 194. 
paulina é um truísmo, 1 Coríntios 15 sozinho exemplifica esse ponto"16. A "ideia" da ressurreição não era um patrimônio comum do judaísmo antigo; os Saduceus, por exemplo, rejeitavam a fé na ressurreição. No entanto, Paulo, como herdeiro da tradição farisaica, abordada em 1.1, atesta a esperança pela ressurreição. De acordo com Brakemeier ${ }^{17}$, seria errôneo qualificar o discurso sobre a ressurreição dos mortos como especulação metafísica, pois está em jogo uma determinada concepção de "realidade". Para o exegeta, a teologia sustenta que dela faz parte uma dimensão "transcendente". Também Lockmann ${ }^{18}$, sob outra perspectiva, considera importante evidenciar a relevância do anúncio da Ressurreição, para Paulo e a Igreja do Novo Testamento, principalmente como força mobilizadora na luta pela vida e inserção nos caminhos históricos do Reino de Deus, e nunca como abstração mística e anti-histórica, capaz de manipular a vida e construir tradições que entronizam a morte e desmobilizam a luta pela vida.

À luz da ressurreição, Blank considera o fim da vida algo novo para o pensamento secularizado e revela-se como segundo nascimento ou renascimento: "Consequentemente, à luz da ressurreição, o fim da vida transforma-se em algo completamente novo para o pensamento secularizado e revela-se como segundo nascimento: renascimento" ${ }^{19}$. Da mesma forma, Brakemeier $^{20}$, registra que ressurreição não deve ser imaginada em analogia ao reavivamento de defuntos. Quem ressuscitou não voltará a morrer jamais. Vive em outras condições, no fundo inimagináveis. Para o exegeta, a fé cristã, muito de acordo com a tradição judaica, não pode conceber existência humana acorporal. Não preconiza a morte como um despir do

${ }^{16}$ STEGNER, W. R. Paulo, o judeu. In: HAWTHORNE, Gerald F.; MARTIN, Ralph P. (Orgs). Dicionário de Paulo e suas cartas. São Paulo: Edições Loyola, 2008, p. 957.

${ }^{17}$ BRAKEMEIER, Gottfried. O ser humano em busca de identidade: contribuições para uma antropologia teológica. São Leopoldo: Sinodal; São Paulo: Paulus, 2002, p. 187.

${ }^{18}$ LOCKMANN, Paulo. 1 Coríntios 15: "A vida que vence a morte". In: GARMUS, Ludovico (Ed). Reflexões bíblicas sobre a vida. Estudos Bíblicos. Voluma 50. São Leopoldo: Sinodal; Petrópolis: Vozes, 1996, p. 92.

${ }^{19}$ BLANK, Renold J. Escatologia da pessoa - Vida, morte e ressurreição. São Paulo: Paulus, 2000, p. 54.

${ }^{20}$ BRAKEMEIER, Gottfried. Panorama da dogmática cristã. São Leopoldo: Sinodal, 2010, p. 122. 
corpo e como libertação da alma desse cativeiro. De acordo com Brakemeier, Paulo está de pleno acordo com Jesus quando sublinha a disparidade entre o velho e o novo. "Ressurreição é outra coisa do que o conserto de cadáveres e a projeção das condições terrestres numa utopia celestial [...] é nova criação que foge à descrição por categorias humanas"21."Na ressurreição Deus toma a criação como ponto de partida, então não é creatio ex nihilo, mas creatio excreatione"22 " "O novo corpo será totalmente diferente do antigo. Não obstante, será a mesma pessoa, assim como os evangelhos o testemunham com respeito ao Jesus ressuscitado"23.

\section{Co 15 como relato pedagógico sobre o fim último do ser humano}

A concepção sobre a ressurreição dos mortos em 1Co 15, na compreensão de Dunn (2003, p. 56), é um dos pontos que torna possível ler a teologia de Paulo a respeito de Deus por não ser apresentada como mero axioma em seu discurso ou teologização. Em 1Co 15, tem-se um excurso acerca da ressurreição e suas consequências para o fiel. É a análise mais detalhada da ressurreição no corpus paulino. O enfoque da análise no capítulo, segundo Kreitzer ${ }^{24}$, não é se Jesus Cristo ressuscitou ou não dentre os mortos, mas sim quais são as consequências da ressurreição de Cristo para o fiel. Também, de acordo com Brakemeier ${ }^{25}$, seria errôneo qualificar o discurso sobre a ressurreição dos mortos como especulação metafísica, pois está em jogo uma determinada concepção de "realidade". Além dela fazer parte uma dimensão "transcendente".

Wiersbe ${ }^{26}$ afirma que nos sermões de Livro de Atos pode-se ver uma ênfase sobre a ressurreição, pois os cristãos foram chamados a ser

${ }^{21}$ BRAKEMEIER, 2010, p. 215.

22 WESTPHAL, Euler R. Imortalidade do ser humano: doutrina filosófica ou ensino bíblico? $2^{\text {a }}$ Parte. In: SCHWAMBACH, Claus (Ed.). VOX SCRIPTURAE. Revista Teológica Brasileira. Vol. XVII/1, julho de 2009, p. 134.

${ }^{23}$ BRAKEMEIER, 2008, p. 211.

${ }^{24}$ KREITZER, L. J. Escatologia. In: HAWTHORNE, Gerald F.; MARTIN, Ralph P. (Orgs). Dicionário de Paulo e suas cartas. São Paulo: Edições Loyola, 2008, p. 465.

25 BRAKEMEIER, 2002, p. 187.

${ }^{26}$ WIERSBE, Warren W. Comentário Bíblico Expositivo: Novo Testamento, volume I. Santo André, SP: Geográfica Editora, 2006, p. 609. 
testemunhas da ressurreição (At 1,21-22; 2,32; 3,15; 5,32), que não deve ser imaginada, segundo Brakemeier ${ }^{27}$, em analogia ao reavivamento de defuntos. Nas palavras de John R. W. Scott: "O cristianismo é, em sua essência, uma religião da ressurreição. $O$ conceito de ressurreição encontra-se em seu cerne. Se o removermos, destruímos o cristianismo"28. "Sem a ressurreição a cruz seria um motivo de desespero. Sem cruz, a ressurreição seria uma fuga da realidade" 29 . Lockmann reconhece que a ressurreição torna-se um tema central da fé cristã, é o novo do anúncio de Jesus e da Igreja; não é mais uma doutrina exótica farisaica, mas uma experiência e fé de toda a comunidade cristã primitiva. A morte, ressalta o exegeta, não é mais algo que intimida e inibe a luta do povo pelo temor que representa, mas sim: “... o último inimigo a ser derrotado”. "A ressurreição representa assim uma libertação no nível simbólico-religioso, com evidente implicação no campo histórico"30.

Paulo anunciou a morte e ressurreição de Jesus Cristo, como sendo a mensagem do evangelho:

Irmãos, venho lembrar-vos ${ }^{31} \mathrm{o}$ evangelho que vos anunciei, o qual recebestes e no qual ainda perseverais; por ele também sois salvos, se retiverdes a palavra tal como vo-la preguei, a menos que tenhais crido em vão. Antes de tudo, vos entreguei o que também recebi:

${ }^{27}$ BRAKEMEIER, 2010, p. 122.

${ }^{28}$ SCOTT, citado por WIERSBE, 2006, p. 609.

${ }^{29}$ DUNN, 2003, p. 281.

${ }^{30}$ LOCKMANN, 1996, p. 89.

${ }^{31}$ Neste capítulo (15) o tom pastoral-doutrinário acerca-se de um estilo mais judaico -rabínico. Isto posto, pode-se entender melhor o jogo de palavras usado por Paulo no início do capítulo 15. Assim, muitos termos que não são usuais em Paulo demonstram que aqui ele depende mais do que nunca de outras fontes. Por exemplo, o verbo gnorizein é usado no sentido de lembrar-se, sentido não utilizado por Paulo em nenhuma das 14 vezes que ele o utiliza em suas cartas, inclusive em 1Co 12,3 (Por isso faço saber a vós...). Neste caso o lembrar-se aqui insere-se no mesmo uso do verbo paralambanein e paradidomi, os quais, embora tenham um amplo e diversificado uso em Paulo, aqui inserem-se na perspectiva do receber a tradição - paralambanein, e entregar a mesma tradição - paradidomi. Tudo dentro de uma dependência evidente do receber e transmitir a tradição recebida. Paulo se reconhece como anunciador euaggelizomaida tradição dos Apóstolos e da Igreja sobre a Ressurreição, mas numa construção perfeitamente rabínica, onde (sic) transmitir a tradição é transmitir a vida (ver LOCKMANN, 1996, p. 88). 
que Cristo morreu pelos nossos pecados, segundo as Escrituras, e que foi sepultado e ressuscitou ao terceiro $\mathrm{dia}^{32}$, segundo as Escrituras. E apareceu a Cefas e, depois, aos doze. Depois, foi visto por mais de quinhentos irmãos de uma só vez, dos quais a maioria sobrevive até agora; porém alguns já dormem. Depois, foi visto por Tiago, mais tarde, por todos os apóstolos e, afinal, depois de todos, foi visto também por mim, como por um nascido fora do tempo (1Co 15,1-8).

"O conteúdo do evangelho paulino pode ser descrito precisamente: a atuação salvífica de Deus em Jesus Cristo, que, sendo o ressuscitado dos mortos, voltará em breve para salvar os crentes da ira de Deus que se abaterá sobre o mundo" 33 . Segundo Schnelle ${ }^{34}$, a expectativa escatológica relacionada com uma futura ressurreição presente em 1Co 15 é provocada pelo entusiasmo ${ }^{35}$ pneumático exagerado dos coríntios, que,

${ }^{32}$ Podemos notar que o "terceiro dia" era uma data simbólica achada com frequência na Escritura. No terceiro dia Abraão "sacrificou" Isaac, isto é, naquele dia Abraão é libertado por uma intervenção de Deus da agonia de ter de sacrificar seu filho (Gn $22,4)$. José liberta os seus irmãos da prisão no "terceiro dia", dizendo-lhes: "Fazei isso e vivereis" (Gn 42,18). Os espiões mandados a Jericó por Josué devem permanecer ocultos por três dias e então poderão escapar sem dano (Js 2,16). É também no terceiro dia que Deus aparece no monte Sinai e dá sua Lei a Moisés (Ex 19,15-16). Poderíamos também referir-nos a Jn 2,1 e a Ed 8,32. Porém o mais provável é que (Paulo) tenha usado o texto de Os 6,1-2. O terceiro é, pois, antes de tudo o dia da libertação; e mais precisamente, já para o judaísmo, é o tempo da libertação escatológica e, portanto, da ressurreição (PATTE, 1987, p. 312). Oseias 6,1-2 teria sido usado por Paulo e o cristianismo primitivo, texto também usado pelos fariseus para falar da ressurreição: "Vinde, e tornemos para o Senhor, porque ele nos despedaçou e nos sarará; fez a ferida e a ligará. Depois de dois dias, nos revigorará; ao terceiro dia, nos levantará, e viveremos diante dele." Este texto estaria na base de todo o querigma cristão sobre a ressurreição ao terceiro dia, mencionada claramente por Paulo (1Co 15,54-55). Na verdade, cremos que o texto de Oseias tem como fundo histórico a guerra Siro-Efraimita e chama ao arrependimento a nação, para sua restauração. O que de todos os modos não anula a releitura do texto de Oseias e outros feita por Paulo e o cristianismo primitivo (LOCKMANN, 1996, pp. 90-91).

${ }^{33}$ SCHNELLE, 2010, p. 232.

34 SCHNELLE, 2010, p. 239.

$35 \mathrm{O}$ que sabemos dos entusiastas é que privilegiavam a vida no aquém em detrimento da vida no além. Procuravam a potenciação da vida hoje, caindo em esquecimento que o perfeito ainda está por vir. Achava-se o viver no céu já nesta terra. Sob tal perspectiva, a esperança pelo mundo vindouro passa a ser secundária. Não que seja abolida. Mas importante mesmo é a vida antes da morte. Associe-se a isso uma 
de acordo com Brakemeier ${ }^{36}$, deve-se predominantemente a distorções na escatologia e, segundo Schnelle ${ }^{37}$, a defesa de uma outra antropologia diversa da paulina.

Diante do juízo de Deus que se abateria sobre todas as pessoas com a volta de Cristo, argumenta Schnelle ${ }^{38}$, cabia a Paulo a tarefa particular de anunciar aos gentios o evangelho da cruz e da ressurreição de Jesus Cristo ("Se anuncio o evangelho, não tenho de que me gloriar, pois sobre mim pesa essa obrigação; porque ai de mim se não pregar o evangelho" 1Co 9,16). Paulo se considerava particularmente apto para essa tarefa; embora ele admita em 1Co 15,9 ser o menor de todos os apóstolos, em razão de sua atuação acossadora.

Para Paulo, a cruz de Cristo é o critério teológico decisivo, ele não argumenta sobre a cruz, ele fala a partir da cruz. [...] Já a Escritura testemunha que a sabedoria de Deus não pode adquirir seu conteúdo a partir da sabedoria do mundo $(1$ Co 1,19$)$. [...] Os coríntios não eclipsaram a cruz, mas eles a neutralizaram ao compreender a morte de Jesus como uma passagem para a verdadeira existência pneumática da qual o pré-existente veio. Dessa forma, eles se apoderaram da atuação divina insondável e identificaram sua sabedoria com a sabedoria de Deus ${ }^{39}$.

Brakemeier admite que, em Corinto, vivia-se uma "escatologia presente" e o apóstolo descobre no entusiasmo coríntio uma perigosa ilusão que redunda em irresponsabilidade e permissividade, pois juntamente com a ressurreição dos mortos também o juízo escatológico fica eliminado. Dessa forma, identifica-se o desenvolvimento da escatologia paulina "supondo-se habitualmente que a demora da parusia enfraqueceu a expectativa imediata de Paulo ou mudou sua ideia do processo pelo qual ocorreu a transformação no corpo da ressurreição" ${ }^{40}$.

\footnotetext{
concepção espiritualizante de ressurreição. Ela não é do corpo, e, sim, do espírito, o que implica uma antropologia dualista (BRAKEMEIER, 2008, p. 199).

36 BRAKEMEIER, 2008, p. 101.

37 SCHNELLE, 2010, p. 275.

38 SCHNELLE, 2010, p. 190.

39 SCHNELLE, 2010, p. 244, 249.

${ }^{40}$ DUNN, 2003, p. 48.
} 
Na pergunta pelo "como" da existência pós-morte, Paulo chega a intelecções novas e modificadas, consideravelmente determinadas pela valoração negativa da corporeidade no pensamento grego. Principalmente sob a influência de ideias platônicas... prevaleceu a visão de que, imediatamente após a morte, a alma imortal separava-se do corpo corruptível, de modo que o corpo não podia ter nenhuma importância para a existência pós-morte. Assim afirma Cícero, Rep. III 28, sobre o arrebatamento de Hércules e Rômulo: "Seus corpos não foram levados para o céu, porque a natureza não toleraria que aquilo que é de terra ficasse em outro lugar se não na terra." Sêneca realça que o corpo é abandonado na morte... Também para Epíteto é claro que o corpo impede a liberdade... Segundo Plutarco sobrevive somente a imagem original que vem dos deuses... Também no judaísmo helenista havia uma grande difusão da opinião de que o corpo estaria sucumbido à corruptibilidade e que só a alma sobreviveria à morte... Contra esse pano de fundo histórico-cultural, Paulo tinha que dar uma resposta acerca da natureza da existência pós-morte, que, por um lado, precisava evitar a ideia de imortalidade da alma, mas que, por outro, não podia eclipsar totalmente a valoração negativa do corpo. Enquanto 1Ts 4,13-18 nem sequer toca na questão e 1Co 15 apresenta uma primeira resposta, particularmente a Segunda Carta aos Coríntios mostra como Paulo se abriu em parte para a argumentação (helenista) das comunidades. Ao mesmo tempo, porém, A Carta aos Romanos e a Carta aos Filipenses mostram que em Paulo dominava a linha de 1Co 15: o corpo transformado pelo espírito (sic) divino preserva a identidade do Eu e pertence, como soma pneumatikon, ao mundo divino ${ }^{41}$.

O discurso da ressurreição na perspectiva voltada para a parusia enquadra-se na "pergunta pelo destino escatológico do ser humano que move o apóstolo"42. "A morte de outras pessoas provoca nas pessoas vivas a pergunta pelo próprio destino, de modo que a escatologia precisa sempre dar também uma resposta convincente sobre o processo de morrer e sobre a morte" ${ }^{43}$. Diante da morte como um questionamento radical de mundos de sentido é inevitável uma abordagem da parusia do Senhor

${ }^{41}$ SCHNELLE, 2010, p. 759-760.

${ }^{42}$ SCHNELLE, 2010, p. 216.

${ }^{43}$ SCHNELLE, 2010, p. 745. 
vinculada à ressurreição de cristãos falecidos. Segundo Schnelle ${ }^{44}$, Paulo precisa fechar uma lacuna entre o primeiro anúncio da parusia realizado na carta mais antiga, 1Ts 4,13-18, e a realidade atual da comunidade.

$\mathrm{Na}$ reflexão sobre a realidade existente além da nossa realidade cotidiana, Mueller ${ }^{45}$ identifica como respostas alguns extremos. Um supõe que o ser humano seja de alguma forma, ou pela própria constituição ou por uma ação externa, sujeito a ser dividido em uma parte física e outra não-física. O que acontece na morte, então, para quem supõe isso, é que a parte física, o corpo, morre e se deteriora, enquanto a parte não-física, a alma ou espírito, sobrevive e vai "diretamente" para junto de Deus ou para um "estado intermediário", aguardar a ressurreição do corpo. Outro, no lado oposto, considera que o ser humano é um todo indivisível e que, quando morre, é esse todo que morre. Fica, então, aguardando a ressurreição, quando Deus fará uma criatura completamente nova, vencendo o poder da morte. E há ainda um outro extremo que considera uma ressurreição "na morte".

A despeito de haver ou não fundamentação para alguma posição adotada, admite Mueller ${ }^{46}$ talvez o maior problema seja o de não se conseguir deixar de pensar em uma vida limitada pelo espaço e pelo tempo. Simplesmente não se consegue pensar que alguma coisa possa existir sem ocupar lugar no espaço e sem estar sujeita ao passar do tempo. Contudo, a realidade mais para lá da que se vive parece realmente estar também mais para lá dessas limitações.

O resultado é que sempre haverá ângulos possíveis de visão, sem considerar-se um dogma em particular, sobre a passagem de uma realidade para outra. "Qualquer reflexão sobre o que vem depois da morte deve sempre contar com essa superação dos nossos limites mais básicos. O problema é que essa superação fica fora dos limites do nosso pensamento"47.

À maneira apocalíptica, afirma Stegner ${ }^{48}$, Paulo fala de uma ressurreição e transformação "corporal" na medida em que se fala de um

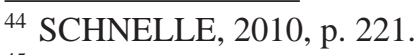

${ }^{45}$ MUELLER, Enio R. O que vem depois da morte? Perguntas \& Respostas da Fé, v. 22. São Leopoldo, RS: Sinodal/FLT, 2000, p. 57.

${ }^{46}$ MUELLER, 2000, p. 57

${ }^{47}$ STEGNER, 2008, p. 957.

${ }^{48}$ STEGNER, 2008, p. 957. 
"corpo espiritual" como corpo. Também Dunn ${ }^{49}$ assevera que seria teologicamente simplista e retoricamente ingênuo tomar a "hipérbole apocalíptica" de Paulo pelo seu valor nominal, sem referência a outros aspectos da sua teologia. Apesar disso, é da maior importância apreciar o sentido de "novidade escatológica" que transformou e continuou a sustentar a teologia de Paulo e não desconsiderá-la totalmente em favor de convicções teológicas mais fáceis de traduzir em termos modernos.

É óbvio, de acordo com Kreitzer ${ }^{50}$, que o pensamento paulino está completamente condicionado por uma perspectiva escatológica na qual a morte e a ressurreição de Jesus Cristo são consideradas, de certa maneira, a inauguração do muito aguardado mundo futuro. Praticamente, toda carta do corpus paulino reflete, em maior ou menor grau, esse ponto de vista escatológico. Muitas áreas fundamentais do ensinamento paulino, como ética, cristologia e eclesiologia, compartilham como base comum essa perspectiva escatológica. Dessa forma considera- se que, "acima de tudo, é a ressurreição de Jesus Cristo que condiciona e determina o ensinamento escatológico paulino, pois é nela que a inauguração da escatologia realmente acontece, que a nova ordem se inicia" ${ }^{51}$.

Intentando demonstrar a esperança escatológica, o apóstolo dos gentios, de forma magistral, lança mão de recursos metafóricos e analogias pertencentes ao universo de seus ouvintes para fazê-los compreender o mistério da transformação. Mazzarolo ${ }^{52}$ desenvolve o artifício paulino apontando para uma espiga de trigo, que todos contemplam e admiramse dos grãos que ela contém. No entanto, não foi semeada uma espiga, nem foi semeada uma pequena planta ou uma gramínea, foi semeado um grão. Qual a relação do grão com a espiga? Onde está o grão que originou a espiga? Essa é a questão difícil de ser assimilada, mas é um exemplo tão prático na natureza. Wiersbe ${ }^{53}$ aponta para o fato de que, quando uma semente é lançada na terra, não se espera que essa mesma semente apareça na colheita. A semente morre, mas dessa morte surge a vida. Podem-se lançar apenas alguns grãos de trigo, mas quando a planta

${ }^{49}$ DUNN, 2003, p. 222.

${ }^{50}$ KREITZER, 2008, p. 477.

${ }^{51}$ KREITZER, 2008, p. 461.

${ }^{52}$ MAZZAROLO, 2008b, p. 204.

${ }^{53}$ WIERSBE, 2006, p. 812. 
atingir a maturidade, haverá muitos grãos. São os mesmos grãos que foram plantados? Não, objeta o exegeta, mas ainda assim há continuidade. Não se semeia trigo para colher-se cevada. Além disso, acrescenta o teólogo, o que aparece na colheita normalmente é mais belo do que o que foi plantado.

A conclusão sobre a ressurreição parece ser não uma questão de retórica, de sofismas ou diatribes, mas de vivência. Como o grão será transformado pela terra em outro ser? (cf. Jo 12,24). A morte não é um fim, mas uma transformação. Nem todos morrerão, mas todos serão transformados. Todos serão transformados porque todos ressuscitarão: uns para a vida e outros para a condenação, mas nem todos morrerão, porquea morte é o julgamento final e a condenação é a segunda morte $(\operatorname{Ap~} 2,11 ; 20.14 ; 21,8)^{54}$.

Para falar do ser humano em sua realidade compósita, segundo $\mathrm{Fa}$ bris ${ }^{55}$, Paulo toma emprestado alguns termos e expressões que podem ser comparados aos da antropologia platônica: "espírito, alma e corpo" (1Ts 5,23). Como os filósofos e os escritores neoplatônicos e estoicos do seu tempo, ele contrapõe o "homem interior" ao "homem exterior", a precariedade das coisas visíveis à imutabilidade das invisíveis (2Co 4,16,18). Paulo, porém, coloca essas categorias dentro de um novo horizonte antropológico, determinado pela visão unitária bíblica, pela novidade da experiência cristã da ressurreição e pelo dom interior do Espírito de Deus.

Silva ${ }^{56}$ entende que, sob a ótica da filosofia, a antropologia distinguese como ciência que estuda o homem do ponto de vista físico-somático e do ponto de vista histórico - sua origem e seus princípios últimos. No entanto, o apóstolo emprega "ho esõ anthrõpos" (Rm 7,22; 2Co 4,16), segundo Silva ${ }^{57}$, para denotar o verdadeiro "Eu" do crente (mundo religioso) ou da pessoa humana (mundo filosófico), conforme se depreende

${ }^{54}$ MAZZAROLO, 2008b, p. 204, ênfase do autor.

55 FABRIS, 2001, p. 60.

56 SILVA, Severino P. da. O homem: corpo, alma e espírito. Rio de Janeiro: CPAD, 1988, p. 110.

57 SILVA, 1988, p. 13. 
"homem interior" como é visto por Deus e parcialmente conhecido por nós na consciência. Da mesma forma, a despeito desse novo horizonte antropológico, Stamps ${ }^{58}$ registra que o corpo é a parte do ser humano que serve de abrigo para a dimensão espiritual, isto é, a alma e o espírito, e que volta ao pó quando a pessoa morre.

Em vista da constatação de sua condição mortal intrínseca, observa Schneider ${ }^{59}$, todo ser humano alimenta o desejo e a esperança de superá-la e atingir uma condição não mortal, condição que é, por definição, divina. Deus é o que garante a existência de nossa imortalidade, não sendo ela uma qualidade intrínseca do ser humano.

Portanto, argumenta conclusivamente Schneider ${ }^{60}$, o ser humano bíblico é criatura mortal; morrendo, ele volta ao pó, de onde foi formado. Tão simples e concreta é a constatação do fim da vida humana. A única esperança do ser humano bíblico é o próprio Deus que o criou. Não existe nele, por si só, algo que por alguma razão pudesse sobreviver ao tempo de vida que Deus lhe destinou, a não ser que o próprio Deus quisesse lhe propiciar tal graça. "O reconhecimento da natureza da humanidade como espécie corpórea conduz diretamente à esperança confiante de que Deus também providenciará ambiente apropriado para a corporificação no mundo vindouro" $"$.

Dessa forma, Dunn ${ }^{62}$ presume que a salvação para Paulo era algo futuro, essencialmente um bem escatológico, algo ainda aguardado, e sua plenitude faz parte do "ainda não". O apóstolo aborda o fenômeno da temporalidade do mundo e do ser humano e procura solucioná-lo no mais estreito vínculo com a cristologia, a antropologia, a soteriologia e a escatologia.

Para tanto, Paulo remete as experiências carismáticas dos coríntios, de acordo com Fabris ${ }^{63}$, as quais unidas à tendência de considerar a

58 STAMPS, Donald C. Bíblia de Estudo Pentecostal. Tradução do texto bíblico de João Ferreira de Almeida, Revista e Corrigida (ARC). Rio de Janeiro, RJ: CPAD, 1995, p. 979-980.

59 SCHNEIDER, Nélio. Alma (corpo, espírito); imortalidade. In: BORTOLLETO FILHO, Fernando (Org.) Dicionário brasileiro de teologia. São Paulo: ASTE, 2008, p. 522 .

60 SCHNEIDER, 2008, p. 523.

${ }^{61}$ DUNN, 2003, p. 137.

${ }^{62}$ DUNN, 2003, p. 534

${ }^{63}$ FABRIS, 2001, p. 471. 
dimensão corpórea e física do ser humano como irrelevante e até mesmo alheia à vida espiritual, fomentam no ambiente de Corinto o terreno de cultivo de uma libertinagem ética avassaladora. Paulo enfrenta os representantes dessa tendência, que ele considera não só extravagante, mas em clara contradição com o núcleo do anúncio da fé cristã. Nesse ponto, Paulo introduz a categoria "corpo", que não se reduz à dimensão física e mortal do ser humano. De fato, corpo tem um futuro indestrutível, pois está em relação com o Senhor ressuscitado. Por isso, Paulo pode dizer que o "corpo não é para a imortalidade e sim para o Senhor, e o Senhor é para o corpo" (1Co 6,13). O termo "corpo", neste caso, corresponde à pessoa, incluindo sua dimensão física e espiritual. Com efeito, o apóstolo conclui essa primeira parte do debate com a afirmação tirada da fé cristã: "Deus, que ressuscitou o Senhor, ressuscitará também a nós pelo seu poder" (1Co 6,14).

A ressurreição é compreendida como uma nova criação, é o revestimento do corpo mortal de incorruptibilidade, é renovação radical (1Co 15,53ss). O corpo físico evidentemente apodrece na sepultura, mas a pessoa ressuscitada receberá novo corpo, espiritual (1Co 15,32s), muito em semelhança ao que na ressurreição de Jesus se revelou aos discípulos.

A imortalidade é real para quem está "em Cristo", afirma Westphal ${ }^{64}$, ou seja, quem experimentou pela fé o juízo e a graça de Deus. Assim, a ressurreição é condição e possibilidade para se falar da imortalidade, ou seja, é o fundamento para a esperança de que depois da morte vem a vida eterna. Assim, o cristão não é um ser para a morte, mas é um ser de esperança e de vida.

\section{Conclusão}

À guisa de conclusão da proposta epistemológica do pensamento paulino:

Hoje pela manhã, detive-me neste pensamento: a criança, no ventre materno, acha-se protegida e provavelmente feliz. Aceita aquele tépido pequeno espaço como seu universo, onde nada lhe falta. Do mundo

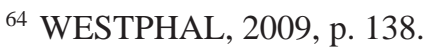


que conhecemos, que ideia pode ela ter? Nenhuma. Admitindo que nos fosse possível comunicar com a criança ainda não nascida, que noção do que seja um livro ou uma casa poderíamos transmitir-lhe? Nenhuma. Vivemos a mesma situação, relativamente ao mundo do além: espraia-se ele em torno de nós, mas só o atingimos com a morte. Encontramo-nos também em um nicho sombrio, onde nos sentimos à vontade, mas só nasceremos, lançando gritos, ao morrermos. Descobriremos, então, um universo de beleza inexprimível... ${ }^{65}$.

Ambígua é a vida. A morte não o é menos. Mais dia menos dia, essa vida terminará. Que fim terá? O homem desaparecerá como as plantas e os animais? Qual o futuro do homem? Como será a vida além túmulo? A morte será o fim de tudo? Essas perguntas têm sido discutidas por filósofos, séculos após séculos. Muitos criam que a alma sobreviveria à morte, como Platão. Poucos no mundo antigo pensavam na morte como extinção do homem: achavam que, depois da morte, alguma coisa continuaria a existir, embora fosse uma existência muitas vezes não pessoal, que realmente não merecia o nome de vida.

"A morte é a maneira de ser que a realidade humana assume desde que passa a existir. Tão logo um homem começa a viver, já é suficientemente velho para morrer" 66 . De acordo com Aubert, esta frase de Heidegger bem exprime a condição da existência humana: "o homem é um ser que sabe que deve morrer”. O ensaísta considera também que desde já se deve situar a morte em sua verdadeira perspectiva: a morte não é, como se diz comumente, o fim da vida; ela invade toda a existência humana.

De todos os seres vivos, o homem é o único que pode figurar antecipadamente sua própria morte e a possibilidade de ver seu ser destruído. É o único capaz de pensar sua própria morte, mesmo quando este acontecimento causa-lhe horror e não queira encarar nem mesmo sua perspectiva ${ }^{67}$.

\footnotetext{
${ }^{65}$ GREEN, citado por AUBERT, Jean-Marie. E depois - vida ou nada?: Ensaio sobre o além. São Paulo: Paulus, 1995, p. 7.

${ }^{66}$ HEIDEGGER, citado por AUBERT, 1995, p. 15.

${ }^{67}$ AUBERT, 1995, p. 15.
} 
Para Aubert ${ }^{68}$, o que caracteriza a morte do ser humano é poder ter, por antecipação, a ideia de sua possibilidade. "Não sabemos imaginar a morte nem nos armar contra ela. Queremos sempre superar esta contingência. A morte é um irrealizável... nunca nos atingirá" ${ }^{69}$. Voltaire escreveu de maneira mais direta: "Nunca devemos pensar na morte. Este pensamento só serve para envenenar a vida"70. "Quer afastemos a ideia da morte, quer continuamente nos apavore, a dura verdade não se torna menos real: a existência humana deve terminar no tempo"71.

Blank assevera que, no plano fenomenológico, constata-se uma tendência nítida do ser humano a fugir da morte. Poder-se-ia indagar, sugere o teólogo, se atrás dessa tendência não se esconde algo mais do que a simples recusa de se ocupar das formas aparentes do fim e da decomposição. Poder-se-ia perguntar também se o temor arcaico do ser humano perante a morte não tem causas mais profundas. "Até hoje, a morte é encarada fundamentalmente como um fim, como o fim da vida. Será que o homem, inconsciente e instintivamente, estaria recusando a aceitar tal fim?"72.

No interesse pelas questões da morte manifesta-se a tentativa do homem de descobrir algo mais sobre um fenômeno de sua existência que conservou o seu caráter de mistério. E atrás de todo o interesse despertado esconde-se talvez uma esperança muito profunda, a esperança de que este mistério não se revele como "mysterium tremendum", a esperança de que a morte não existe como fim e perecimento da vida ${ }^{73}$.

A morte é uma necessidade biológica universal.O homem é um "cadáver adiado que procria" afirmou o poeta português Fernando Pessoa em sua poesia "Mensagem".'Morremos porque somos pó. Esta é a lei da natureza, à qual nos submetemos como os demais seres [...]. A morte não é apenas um acontecimento; é um estado"74. "Para os que têm esperança em uma vida futura, a morte é uma grande libertadora. Ela corta as ligaduras

${ }^{68}$ AUBERT, 1995, p. 15.

${ }^{69}$ SARTRE, J. P. O ser e o nada. [Sl: s.n.], 1942, p. 33.

${ }^{70}$ VOLTAIRE. Correspondance. Tomo 47. Genebra: Ed. Besterman, 1959, p. 124.

${ }^{71}$ AUBERT, 1995, p. 16.

${ }^{72}$ BLANK, 2000, p. 12.

${ }^{73}$ BLANK, 2000, p. 12-13.

${ }^{74}$ LEITE FILHO, Tácito da G. O Homem em três tempos. Rio de Janeiro: CPAD, 1982, p. 81. 
que prendem a alma ao corpo e permite que a alma vá à sua pátria eterna, assim pensava Sócrates, que defendia a imortalidade da alma"75.

A abordagem ora realizada não tem o escopo de revisar ou formar teologúmenos. Conquanto procure desenvolver um tema específico, implica uma série de leituras centradas sobre questões específicas, que buscam esclarecer aos poucos o sistema paulino de convicções e seu modelo. Temas centrais encontrados nas cartas permitem perceber, reconhece Patte $^{76}$, como a fé do apóstolo mantém unidas as suas várias percepções da natureza humana, da sociedade e da cultura, do mundo e da história, de outras religiões e sua relação com o evangelho, bem como sua visão da igreja e da vida cristã em relação com Deus, com Jesus Cristo, com o Espírito divino e com a Escritura.

Em harmonia com esse pensamento, Dunn registra que

a concepção paulina da pessoa humana é a de um ser que funciona dentro de várias dimensões. Como seres corporificados, somos sociais, definidos em parte pela nossa necessidade e nossa capacidade de entrar em relação, não como um opcional extra, mas como uma dimensão da nossa própria existência. Nossa carnalidade atesta nossa fragilidade e fraqueza como meros humanos, a inevitabilidade da nossa morte, nossa dependência da satisfação dos apetites e desejos. Ao mesmo tempo, como seres racionais, somos capazes de nos alçar às maiores alturas do pensamento reflexivo. E como seres que sentem somos capazes das mais profundas emoções e da mais intensa motivação. Somos seres vivos, animados pelo mistério da vida como um dom, e há uma dimensão do nosso ser pela qual somos diretamente tocados pela realidade mais profunda dentro e além do universo. Paulo não duvidaria em dizer, grato e reconhecido, com o salmista: "Eu te celebro por tão grande prodígio, eu me maravilho com as tuas maravilhas" $(\text { Sl 139,14) })^{77}$.

Embora a morte seja temática frequente no Novo Testamento, admite Lockmann ${ }^{78}$, ela não pode ser considerada isolada e como definitiva,

\footnotetext{
75 LEITE FILHO, 1982, p. 82.

76 PATTE, Daniel. Paulo, sua fé e a força do Evangelho: introdução estrutural às cartas de São Paulo. São Paulo: Paulinas, 1987, p. 56.

77 DUNN, 2003, p. 112.

${ }^{78}$ LOCKMANN, 1996, p. 86.
} 
mas sim como circunstancial e como verdadeiro pórtico para introdução do tema da vida e da esperança. Pensamento do qual compartilhamos e que, pensamos, Paulo desenvolve com maestria em 1 Coríntios 15. Contudo, "a perspectiva do triunfo sobre a morte não justifica nenhum triunfalismo cristão. Exigindo sobriedade, ela possibilita, isto sim, uma atitude de firmeza que não se abala com as contradições de um mundo em transição" ${ }^{79}$.

Fabris ${ }^{80}$ considera ainda que cada época procura reler e reinterpretar a pessoa de Paulo segundo os próprios modelos culturais, projetando seus esquemas ou valores ideais. Em todo caso, admite o biblista, quem entra em contato com a personalidade e o pensamento de Paulo não pode permanecer neutro. Até a reação desconfiada e, em alguns casos, hostil em relação a Paulo, desde os primeiros séculos cristãos até nossos dias, é uma confirmação desse destino histórico do Apóstolo.

Quem tem a oportunidade ou a felicidade de conhecer, pelas cartas, o seu modo de viver e repensar a experiência da fé cristã, em todas as ressonâncias profundamente humanas, sente o fascínio da sua personalidade. Mesmo que Paulo não possa ser considerado o "fundador" do Cristianismo, ele continua sendo uma testemunha qualificada e decisiva para compreender o impacto que essa experiência religiosa teve na história da humanidade ${ }^{81}$.

Dessa forma, pode-se dizer que a religião confere às realidades frágeis do mundo social o fundamento de um realissimum sagrado que se encontra por definitionem além das casualidades das buscas e procuras humanas. Assim,

a adoção de problemas da sociologia do conhecimento parte do pressuposto de que afirmações teológicas também estão sempre inseridas num contexto social que é um dos componentes que determina sua formação e sua compreensão. No entanto, com isso não se adota os pressupostos ideológicos de um construtivismo radical, frequentemente

\footnotetext{
${ }_{79}$ BRAKEMEIR, 2008, p. 218.

${ }^{80}$ FABRIS, 2001, p. 731-732.

${ }^{81}$ FABRIS, 2001, p. 732.
} 
predominante em conceitos sociológicos e filosóficos ${ }^{82}$, segundo o qual toda realidade e, com isso, também a religião, é exclusivamente construída, e ainda segundo o qual nós geramos o mundo no qual vivemos ao viver nele. Os teóricos construtivistas precisam aceitar que suas próprias teorias são uma construção. [...] A religião forma o mundo simbólico de sentido por excelência, pois, em medida muito maior que o direito, esboços filosóficos ou ideologias políticas, ela tem a pretensão de representar aquela realidade única que transcende todas as realidades: Deus ou o Sagrado, respectivamente. Como realidade abrangente, sempre pré-estabelecida em relação ao ser humano, a religião é capaz de oferecer um mundo de sentido que, principalmente com a ajuda de símbolos, confere ao indivíduo e ao grupo seu lugar na ordem do conjunto do cosmo, que interpreta os fenômenos da vida, oferece orientações para a atuação e finalmente abre perspectivas para além da morte ${ }^{83}$.

\section{Referências}

AUBERT, Jean-Marie. E depois - vida ou nada?: Ensaio sobre o além. São Paulo: Paulus, 1995.

BÍBLIA DE JERUSALÉM. Novo Testamento. São Paulo: Paulus, 1994. BÍBLIA SAGRADA (A). Tradução Ecumênica (TEB). Edição Revista e Corrigida. São Paulo: Edições Loyola, 1995.

BÍBLIA SAGRADA. Tradução de João Ferreira de Almeida, Revista e Atualizada (ARA). $2^{a}$ edição. São Paulo: Sociedade Bíblica do Brasil, 1993.

BLANK, Renold J. Escatologia da pessoa - Vida, morte e ressurreição. São Paulo: Paulus, 2000.

BRAKEMEIER, Gottfried. O ser humano em busca de identidade: contribuições para uma antropologia teológica. São Leopoldo: Sinodal; São Paulo: Paulus, 2002.

\footnotetext{
82 "Em virtude de sua própria lógica, a teoria sociológica precisa considerar a religião como projeção humana, e em virtude desta mesma lógica, ela não tem nada a afirmar sobre a pergunta se essa projeção se dirige a algo que é diferente da natureza do projetor [...]. Quando se postula uma visão de mundo religioso, os próprios fundamentos antropológicos dessa projeção poderiam ser reflexos de uma realidade que transcende tanto o mundo como o ser humano" (BERGER, citado por SCHNELLE, 2010, p. 36).

${ }^{83}$ SCHNELLE, 2010, p. 36-37.
} 
BRAKEMEIER, Gottfried. A Primeira Carta do Apóstolo Paulo à comunidade de Corinto: um comentário exegético-teológico. São Leopoldo: Sinodal / EST, 2008.

BRAKEMEIER, Gottfried. Panorama da dogmática cristã. São Leopoldo: Sinodal, 2010.

DUNN, James D. G. A teologia do apóstolo Paulo. São Paulo: Paulus, 2003.

FABRIS, Rinaldo. Paulo: Apóstolo dos gentios. São Paulo: Paulinas, 2001.

IDÍGORAS, J. L. Vocabulário teológico para a América Latina. São Paulo: Edições Paulinas, 1983.

KREITZER, L. J. Escatologia. In: HAWTHORNE, Gerald F.; MARTIN, Ralph P. (Orgs). Dicionário de Paulo e suas cartas. São Paulo: Edições Loyola, 2008.

LEITE FILHO, Tácito da G. O Homem em três tempos. Rio de Janeiro: CPAD, 1982.

LOCKMANN, Paulo. 1 Coríntios 15: “A vida que vence a morte". In: GARMUS, Ludovico (Ed). Reflexões bíblicas sobre a vida. Estudos Bíblicos. Voluma 50. São Leopoldo: Sinodal; Petrópolis: Vozes, 1996.

MAZZAROLO, Isidoro. O Apóstolo Paulo: O Grego, o Judeu e o Cristão. Rio de Janeiro: Mazzarolo editor, 2008a.

MAZZAROLO, Isidoro. Primeira Carta aos Coríntios, exegese e comentário. Rio de Janeiro: Mazzarolo editor, 2008b.

MUELLER, Enio R. O que vem depois da morte? Perguntas \& Respostas da Fé, v. 22. São Leopoldo, RS: Sinodal/FLT, 2000.

PATTE, Daniel. Paulo, sua fé e a força do Evangelho: introdução estrutural às cartas de São Paulo. São Paulo: Paulinas, 1987.

SARTRE, J. P. O ser e o nada. [Sl: s.n.], 1942.

SCHNEIDER, Nélio. Esperar em Cristo somente para esta vida? (1Co 15,19): A felicidade brota da transcendência. Bíblia e Utopia. Estudos Bíblicos. Voluma 49. São Leopoldo: Sinodal; Petrópolis: Vozes, 1996.

SCHNEIDER, Nélio. Alma (corpo, espírito); imortalidade. In: BORTOLLETO FILHO, Fernando (Org.) Dicionário brasileiro de teologia. São Paulo: ASTE, 2008.

SCHNELLE, Udo. Paulo: vida e pensamento. Santo André (SP): Academia Cristã: São Paulo: Paulus, 2010.

SILVA, Severino P. da. O homem: corpo, alma e espírito. Rio de Janeiro: CPAD, 1988. 
STAMPS, Donald C. Bíblia de Estudo Pentecostal. Tradução do texto bíblico de João Ferreira de Almeida, Revista e Corrigida (ARC). Rio de Janeiro, RJ: CPAD, 1995.

STEGNER, W. R. Paulo, o judeu. In: HAWTHORNE, Gerald F.; MARTIN, Ralph P. (Orgs). Dicionário de Paulo e suas cartas. São Paulo: Edições Loyola, 2008.

VOLTAIRE. Correspondance. Genebra: Ed. Besterman, 1959.

WESTPHAL, Euler R. Imortalidade do ser humano: doutrina filosófica ou ensino bíblico? $2^{\mathrm{a}}$ Parte. In: SCHWAMBACH, Claus (Ed.). VOX SCRIPTURAE. Revista Teológica Brasileira. Vol. XVII/1, julho de 2009. WIERSBE, Warren W. Comentário Bíblico Expositivo: Novo Testamento. Volume I. Santo André, SP: Geográfica Editora, 2006.

Submetido em: 26/02/2018 Aceito em: 25/06/2018 